\title{
More than 9 years of continuous trastuzumab treatment in metastatic breast cancer without cardiac toxicity: a case report and literature review
}

\author{
This article was published in the following Dove Press journal: \\ OncoTargets and Therapy \\ 17 October 2014 \\ Number of times this article has been viewed
}

\author{
Florin Badulescu' \\ Adriana Badulescu ${ }^{2}$ \\ Doru Paul ${ }^{3}$ \\ Carmen Florina Popescu ${ }^{4}$ \\ Cristina Florescu ${ }^{5}$ \\ 'Department of Oncology, \\ Universitatea de Medicina si Farmacie, \\ Craiova, Romania; ${ }^{2}$ Department of \\ Surgery, Universitatea Titu Maiorescu, \\ Bucuresti, Romania; ${ }^{3}$ Monter Cancer \\ Center, North Shore LIJ Cancer \\ Institute, Lake Success, NY, USA; \\ ${ }^{4}$ Department of Pathology, Spitalul \\ Universitar Clinic de Urgenta, \\ Craiova, Romania; ${ }^{5}$ Department of \\ Cardiology, Universitatea de Medicina \\ si Farmacie, Craiova, Romania
}

\begin{abstract}
The main concern of long-term use of trastuzumab remains its association with potential cardiac side effects. Although these side effects are real, they are probably overemphasized. We report the case of a woman with metastatic breast cancer, who is currently in complete remission, and who received trastuzumab continuously for more than 9 years, without any significant cardiac toxicity.
\end{abstract}

Keywords: metastatic breast cancer, long survival, trastuzumab

\section{Introduction}

Trastuzumab $\left(\right.$ Herceptin $\left.^{\circledR}\right)$ is a humanized monoclonal antibody inhibitor of the human epidermal growth factor receptor 2 (Her2/neu). Her2/neu, a transmembrane tyrosine kinase receptor belonging to the epidermal growth factor receptor family is overexpressed in approximately $20 \%$ of invasive breast cancers. Activation of Her 2 has been shown to result in tumor growth and progression.

Since its approval in the USA in 1998, trastuzumab has revolutionized the management of localized Her2/neu-positive breast cancer, especially in those who express the Her2/neu protein. According to observational data, the use of trastuzumab in women with early breast cancer has reversed the worst prognosis associated with Her2-positive status. In a multivariate analysis published in 2010, trastuzumab recipients with Her2/neu-positive disease had a $44 \%$ reduction in the risk of death, versus women with Her2-negative disease (hazard ratio [HR]: 0.56, 95\% confidence interval [CI]: $0.45-0.69 ; P<0.0001){ }^{1}$

Additionally, trastuzumab has been shown to improve both the progression-free survival (PFS) and the overall survival (OS) rate of patients with metastatic breast cancer. In a pivotal Phase III trial, trastuzumab, in combination with chemotherapy, was administered as first-line therapy to Her2-positive metastatic breast cancer patients. The time to disease progression was significantly prolonged ( 7.4 months versus 4.6 months). Also, the OS rates (25 months versus 20 months) improved, when compared against chemotherapy alone. $^{2}$

It is not clear if continuing trastuzumab after progression improves the OS of women with metastatic breast cancer. Accordingly, the final overall analysis of the GBG-26/ BIG 3-05 Phase III study did not demonstrate a significant survival benefit for treatment beyond progression with trastuzumab. In the same study, a non-planned, post hoc
Monter Cancer Center, North Shore LIJ

Cancer Institute, 450 Lakeville Road, Lake

Success, NY I 1042, USA

$\mathrm{Tel}+\mathrm{I} 5167348775$

Fax +I 5167348924

Email dpaul4@nshs.edu 
analysis suggested that patients receiving anti-Her2 treatment as third-line therapy may benefit from trastuzumab, as they had better postprogression survival than those not receiving the treatment (18.8 months versus 13.3 months; HR:0.63; $P=0.02){ }^{3}$

Trastuzumab is an effective targeted agent. However, it is estimated that, for each life saved, 10-25 patients develop heart disease. For example, the N9831 (Arm C) and NSABP B31 joint analysis revealed that, on average, for every three lives saved by reducing breast cancer, two patients died of heart disease or other complications. ${ }^{4}$ Slamon et al reported a $27 \%$ incidence of cardiac events in patients treated with the combination anthracyclines-trastuzumab, compared against $12 \%$ with the combination paclitaxel-trastuzumab. ${ }^{2}$

Despite the introduction of trastuzumab, Her2/neu-positive metastatic breast cancer remains an aggressive disease, and the majority of patients progress within 1 year of starting the treatment.

Here, we present the case of a postmenopausal woman with metastatic breast cancer, currently in complete remission, who received trastuzumab for more than 9 years, without any significant cardiac toxicity.

\section{Case report}

In July 2005, a 53-year-old woman presented to a medical oncologist with a complaint of a left breast mass, of several years duration. The patient was in very good health otherwise, without any comorbidities, and she was taking no medications. On physical examination, peau d'orange was noted in her left breast (Figure 1) and a subcentimetric mass was palpable above her left nipple. Several enlarged lymph nodes were also palpable in her left axilla. The tumor was biopsied and the biopsy results revealed tubular breast

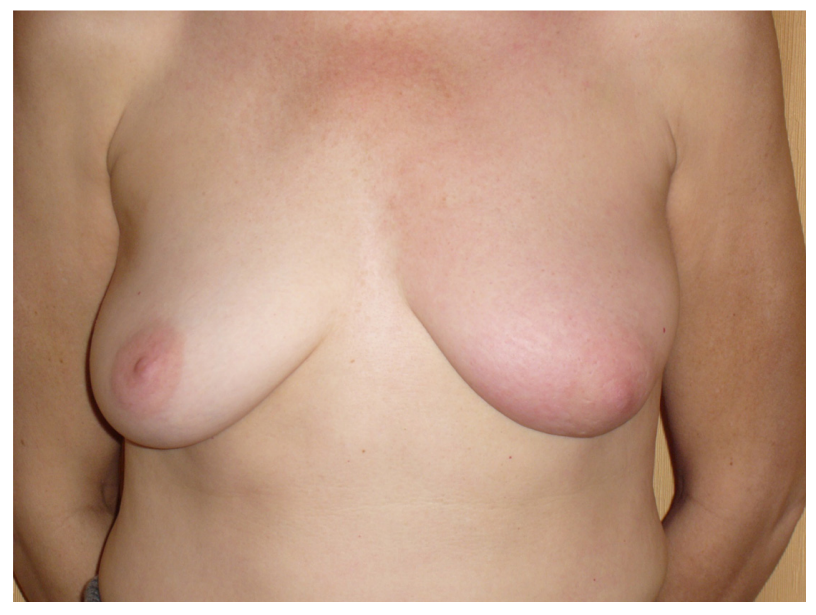

Figure I Image of the inflammatory breast lesion in June 2005. carcinoma (Figure 2). The tumor was found to be estrogen receptor-(ER) positive $(40 \%-50 \%)$ (Figure 3), progesterone receptor-(PR) positive (10\%-15\%) (Figure 4), and Her $2 /$ neu positive (2+) (Figure 5). Her2/neu positivity was confirmed by fluorescence in situ hybridization. The patient had a computed tomography (CT) of the chest/abdomen/pelvis, which revealed bilateral lung and spinal bone metastasis. At that time, she was staged clinically as T4cN2M1.

The patient was treated for more than 1 year with docetaxel $\left(70 \mathrm{mg} / \mathrm{m}^{2}\right)$ every 3 weeks, in combination with weekly trastuzumab ( $2 \mathrm{mg} / \mathrm{kg})$, with good clinical response. The erythema of the skin improved and the breast tumor was no longer palpable. In September 2006, she had a modified radical mastectomy with axillary dissection. The mastectomy specimen was found to be cancer-free, and all ten lymph nodes removed from the axilla were negative (pathological stage: T0N0Mx). Postoperatively, the patient continued to receive docetaxel $\left(70 \mathrm{mg} / \mathrm{m}^{2}\right)$ and trastuzumab for more than 2 years, until December 7, 2008. Of note, on an echocardiogram done in February 2008, the ejection fraction was slightly decreased (48\%). Given the fact she did not have any cardiac symptoms, the decision was made to continue the weekly trastuzumab treatment. On a follow-up echocardiogram done 3 months later, the ejection fraction had normalized (53\%).

In December 2008, the patient was found to have evolving pulmonary metastasis, in addition to new bone metastasis. At that time, the patient was given four cycles of docetaxel $\left(70 \mathrm{mg} / \mathrm{m}^{2}\right)$ and epirubicin $\left(90 \mathrm{mg} / \mathrm{m}^{2}\right)$, with minimal response, followed by four cycles of gemcitabine $\left(1,250 \mathrm{mg} / \mathrm{m}^{2}\right)$ and cisplatin $\left(75 \mathrm{mg} / \mathrm{m}^{2}\right)$, which were subsequently followed by two more cycles of gemcitabine

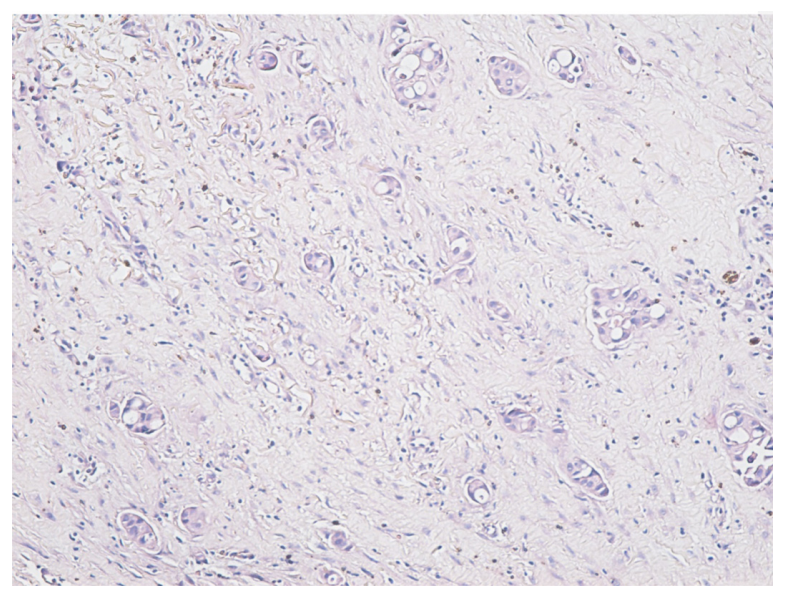

Figure 2 Breast biopsy - sheets of malignant ductal cells in an invasive ductal carcinoma moderately differentiated (G2), H\&E stain, I00x.

Abbreviation: H\&E, hematoxylin and eosin. 


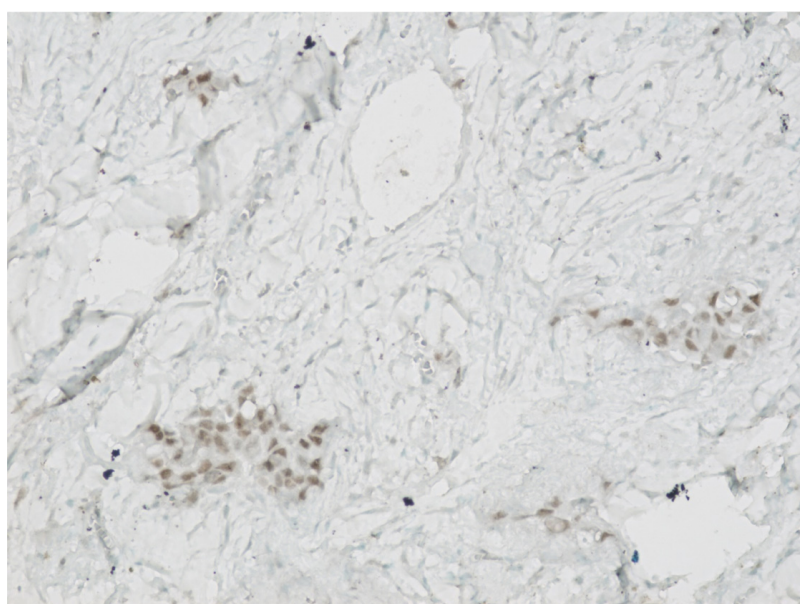

Figure 3 Breast biopsy - positive nuclear immunostaining for estrogen receptors (semiquantitative evaluation is $40 \%-50 \%$ ), LSAB technique, $200 \times$.

Abbreviation: LSAB, labeled streptavidin biotin.

$\left(1,250 \mathrm{mg} / \mathrm{m}^{2}\right)$ and carboplatin (area under the curve $\left.=5\right)$ (cisplatin was changed to carboplatin because of renal toxicity), with excellent response.

In June 2009, CT scan of the chest revealed a normal study, and her bone scan did not show any evidence of active bone disease. At that point, the patient had received a total of 141 weekly cycles of trastuzumab. In July 2009, the patient was started on letrozole ( $2.5 \mathrm{mg}$ orally per day) and trastuzumab ( $2 \mathrm{mg} / \mathrm{kg}$ ) every 2 weeks and, until July 2014, received an additional 92 cycles of biweekly trastuzumab. A CT of the chest and an echocardiogram, performed in June 2014, were normal.

The foregoing indicates that, in this patient, the continuous trastuzumab treatment was generally well tolerated. The only notable complication was a paronychial infection, which resolved entirely with antibiotic treatment.

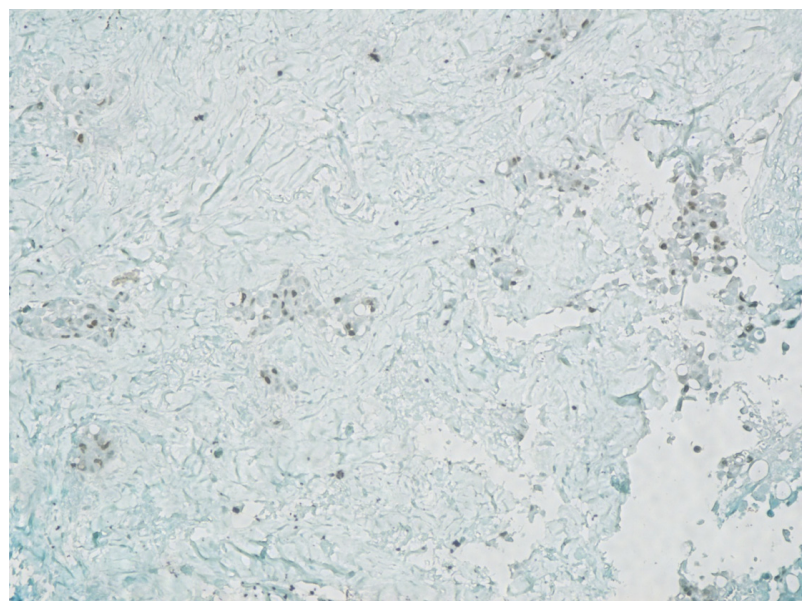

Figure 4 Breast biopsy - positive nuclear immunostaining for progesterone receptors (semiquantitative evaluation is 10\%-15\%), LSAB technique, 100x. Abbreviation: LSAB, labeled streptavidin biotin.

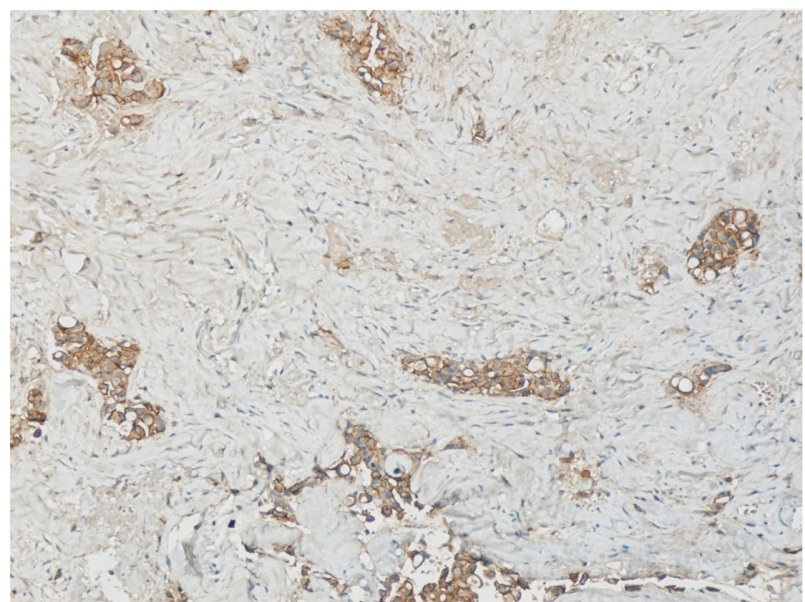

Figure 5 Breast biopsy - positive incomplete membrane immunostaining for c-erbB2 protein (score 2+), LSAB technique, 100x.

Abbreviation: LSAB, labeled streptavidin biotin.

To summarize, over the duration of more than 9 years, from June 2005 to July 2014, the patient received 233 doses of $150 \mathrm{mg}$ trastuzumab, without significant cardiac toxicity. The most recent echocardiogram, performed in June 2014, was normal (ejection fraction: 60\%).

\section{Discussion}

We report the case of a patient who was diagnosed with bone and bilateral lung metastatic breast cancer, and who was still alive and disease-free after 9 years of continuous treatment with trastuzumab, in combination with chemotherapy or hormonal treatment.

There are several factors that may have contributed to the exceptionally long survival of this patient.

First, several retrospective studies indicate that, in the setting of metastatic disease, women who undergo surgical resection of the primary tumor have longer survival than those whose primary tumor is left intact..$^{5-7}$ After receiving 1 year of neoadjuvant chemotherapy, this patient also had local treatment of her primary tumor, but both the mastectomy tissue and the resected lymph nodes were cancer-free.

Also, postsurgery, this patient received various chemotherapy regimens in combination with trastuzumab for more than 30 months. Subsequently, after achieving complete remission, trastuzumab was continued in combination with hormonal treatment. Hence, it is difficult to determine which of the agents used - chemotherapy, hormonal therapy, or trastuzumab - had the highest contribution to her long survival.

In September 1998, the US Food and Drug Administration approved trastuzumab as a first-line therapy for Her2-positive metastatic breast cancer. The approval was based on the 
observation that, in women with advanced Her2-positive breast cancer, the up front use of trastuzumab, in combination with chemotherapy, prolongs life.

In the English literature, there are several published case reports of prolonged survival rates associated with longterm trastuzumab use. ${ }^{8-12}$ However, in none of these cases was trastuzumab administered for such a long time as in our patient (longer than 9 years) (Table 1). All five of the patients described in the case reports presented initially with localized disease, and had surgery. The patient described here had metastatic disease on presentation and had surgery more than 1 year from diagnosis, after demonstrating an exceptionally favorable response to chemotherapy and trastuzumab. In two of the five previously published case reports, trastuzumab was administered as a single agent, ${ }^{10,11}$ and in one case it was given in combination with chemotherapy. ${ }^{12}$

In two cases, it was initially used in combination with chemotherapy and then alone in maintenance. ${ }^{8,9}$ Interestingly, the tumors of all these five patients were hormone receptor-negative, as opposed to the tumor of our patient, which was hormone receptor-positive. Also, our patient was older ( 53 years) than the patients described in the previously published case reports (Table 1).

In 2012, a series of 217 patients with Her2/neu-positive breast cancer was reported at the Thirty-Fifth Annual CTRC-AACR San Antonio Breast Cancer Symposium. ${ }^{13}$ Fifty-six (26\%) of these patients survived longer than 5 years. The median disease-free interval was 17 months. In 39 cases (70\%), the tumors were hormone receptor-positive. Of note, all the complete responses were observed after one line of taxane-based chemotherapy, given in combination with trastuzumab. Seven patients who had a complete response continued trastuzumab, and all hormone receptor-positive patients received hormonotherapy as well.

An analysis of the characteristics of the demographics, disease characteristics, and treatment history of patients with metastatic breast cancer treated with trastuzumab was also presented in 2012 in San Francisco at the ASCO Breast Cancer Symposium. ${ }^{14}$ RegistHER was a multicenter, prospective, observational, US-based cohort study of 1,023 patients with Her2/neu-positive metastatic breast cancer diagnosed within 6 months of enrollment. The objectives of the

Table I Previously published case reports

\begin{tabular}{|c|c|c|c|}
\hline $\begin{array}{l}\text { Year of publication } \\
\text { and reference number }\end{array}$ & $\begin{array}{l}\text { Age at diagnosis } \\
\text { Stage at diagnosis } \\
\text { Histology status } \\
\text { Receptor status } \\
\text { Surgery performed }\end{array}$ & $\begin{array}{l}\text { Location of metastasis } \\
\text { Duration of trastuzumab use }\end{array}$ & Treatment administered \\
\hline $2005^{\prime \prime}$ & $\begin{array}{l}43 \\
\text { Stage IIB } \\
\text { Invasive ductal } \\
\text { ER-PR-Her2/neu 3+ } \\
\text { Mastectomy }\end{array}$ & $\begin{array}{l}\text { Liver } \\
3 \text { years and } 9 \text { months }\end{array}$ & Trastuzumab alone weekly \\
\hline $2006^{10}$ & $\begin{array}{l}36 \\
\text { Stage IIB } \\
\text { Invasive ductal } \\
\text { ER-PR-Her2/neu 3+ } \\
\text { Mastectomy }\end{array}$ & $\begin{array}{l}\text { Liver } \\
5 \text { months }\end{array}$ & Trastuzumab alone, every 3 weeks \\
\hline $2007^{9}$ & $\begin{array}{l}46 \\
\text { Stage IIIA } \\
\text { Invasive ductal } \\
\text { ER-PR-Her2/neu 3+ } \\
\text { Lumpectomy }\end{array}$ & $\begin{array}{l}\text { Liver } \\
2 \text { years and } 2 \text { months }\end{array}$ & $\begin{array}{l}\text { Trastuzumab every } 3 \text { weeks, } \\
\text { with paclitaxel weekly for } 4 \text { months, } \\
\text { then trastuzumab alone }\end{array}$ \\
\hline $2010^{8}$ & $\begin{array}{l}34 \\
\text { Stage IIIA } \\
\text { Invasive ductal } \\
\text { ER-PR-Her2/neu 3+ } \\
\text { Mastectomy }\end{array}$ & $\begin{array}{l}\text { Liver } \\
7 \text { years }\end{array}$ & $\begin{array}{l}\text { Trastuzumab weekly, with 5FU- } \\
\text { LV-MTX for } 4 \text { months, } \\
\text { then with vinorelbine } \\
\text { and gemcitabine for } 9 \text { months, } \\
\text { then trastuzumab alone, weekly }\end{array}$ \\
\hline $2012^{12}$ & $\begin{array}{l}29 \\
\text { Stage IIIB } \\
\text { Invasive ductal } \\
\text { ER-PR-Her2/neu overexpressed } \\
\text { Mastectomy }\end{array}$ & $\begin{array}{l}\text { Pulmonary and bone metastases } \\
5 \text { years }\end{array}$ & $\begin{array}{l}\text { Trastuzumab every } 4 \text { weeks, } \\
\text { with capecitabine for } 2 \text { weeks on/ } \\
\text { I week off }\end{array}$ \\
\hline
\end{tabular}

Abbreviations: Her2/neu, human epidermal growth factor receptor 2; ER, estrogen receptor; PR, progesterone receptor; 5 FU, 5 fluorouracil; LV, leucovorin; MTX, methotrexate. 
registHER study were to describe the natural disease history and treatment patterns for patients with Her2/neu-positive metastatic breast cancer, and to investigate the associations between different treatments and outcomes. There were 404 patients in the registry found to have long-term survival (LTS). LTS was defined as survival $\geq 36$ months from metastatic diagnosis. Of the LTS patients, 356 were treated with front-line therapy, and 106 of them (29.8\%), received chemotherapy and hormonal treatment, in addition to trastuzumab. Prognostic factors associated with OS in all treated patients were assessed using multivariate Cox regression analysis. Factors associated with reduced risk of mortality included: ER-positive or PR-positive disease; metastasis to bone only, or bone plus breast or node/local sites; first-line trastuzumab use; and first-line taxane use.

The authors of the registHER study also recently published an updated report. ${ }^{15}$ In this report, they found that, compared against patients who received first-line trastuzumab and chemotherapy only, patients who received first-line trastuzumab and chemotherapy in addition to hormonal therapy had longer median PFS times (20.4 months versus 9.5 months; adjusted HR: 0.53, 95\% CI: 0.42-0.68); a statistically significant reduction in the risk of death was observed (adjusted HR: 0.50, 95\% CI: 0.36-0.70). Also, sequential use of chemotherapy and hormonal therapy was associated with improved OS times, when compared against concurrent use (adjusted PFS HR: 0.81, 95\% CI: 0.54-1.21; adjusted OS HR: 0.48, 95\% CI: 0.26-0.89).

The patient described here was treated with both frontline taxanes and trastuzumab, and had a hormone receptorpositive breast cancer. Based on the registHER study findings, this may have contributed to the good initial response and to the subsequent relatively indolent course of her disease. On the other hand, given the presence of bilateral lung and bone metastasis, our patient fits only partially the favorable prognostic criteria described in the registHER study.

Clinical evidence supports continued trastuzumab treatment after initial progression. For example, a prospective, randomized, German study, ${ }^{3}$ in which 112 patients with Her2-positive metastatic breast cancer, initially progressed on a trastuzumab-based therapy (GBG-26/BIG 3-05 study), showed that the patients enrolled in the trastuzumabcapecitabine arm had a longer PFS (8.2 months versus 5.6 months) and OS (25.5 months versus 20.4 month), compared against patients enrolled in the capecitabine only arm, but the improvement in OS was not statistically significant $(P=0.257) .^{3}$ Trastuzumab was also continued in our patient, after initial progression, in combination with two different chemotherapy regimens. Hence, this may explain this patient's long PFS.

Notwithstanding the above, the main concern of longterm use of trastuzumab remains the potential cardiac side effects. A very thorough definition of cardiotoxicity was formulated by the cardiac review and evaluation committee (CREC) supervising the trastuzumab clinical trials. ${ }^{16}$ CREC established the following criteria to confirm or revise a preliminary diagnosis of cardiac disease: 1) cardiomyopathy characterized by a decrease in cardiac left ventricular ejection fraction (LVEF) that was either global or more severe in the septum; 2) symptoms of congestive heart failure (CHF); 3 ) associated signs of CHF, including, but not limited to, S3 gallop, tachycardia, or both; and 4) decline in LVEF of at least $5 \%$, to less than $55 \%$, with accompanying signs or symptoms of $\mathrm{CHF}$, or a decline in LVEF of at least $10 \%$, to below $55 \%$, without accompanying signs or symptoms. ${ }^{16}$

The degree of cardiotoxicity induced by trastuzumab varies, and it ranges from asymptomatic left ventricular dysfunction, diagnosed during the routine follow-up by a decrease in the ejection fraction, to severe symptomatic $\mathrm{CHF}$, although the latter is a rare event, occurring in less than $3 \%$ of patients treated with trastuzumab. ${ }^{17}$ As opposed to Type I chemotherapy-related cardiac dysfunction (CRCD), caused by classical chemotherapy agents such as anthracyclines, alkylating drugs, and microtubule inhibitors, trastuzumab has been associated with Type II CRCD, which is a completely different entity. ${ }^{18}$ The characteristics of Type II CRCD are: it is not dose-related; it occurs only in a fraction of patients; it appears to be highly reversible, in contrast with Type I $\mathrm{CRCD} ;{ }^{16}$ it has a high likelihood of recovery, even when the drug is continued; ${ }^{19}$ its severity widely varies; and it is not associated with identifiable ultrastructural abnormalities (reviewed in Ewer and Lippman). ${ }^{18}$ In a meta-analysis published in 2008 that included 9,117 patients, there were more cardiac toxicities of Grade 3 or 4 after trastuzumab use $(203 / 4,555 ; 4.5 \%)$ compared against no trastuzumab $(86 / 4,562)$, and the likelihood of cardiotoxicity was 2.45 fold higher in trastuzumab-treated patients. ${ }^{20}$ Also, in the registHER study, in the cohort of LTS patients, the incidence of any cardiac safety event (Grade $\geq 3$ ) was $8.9 \%$, and this was only slightly higher than in all treated patients $(7.8 \%)$. Left ventricular dysfunction was the most prevalent cardiac adverse event in LTS (5.0\%), as well as in all treated patients $(2.6 \%){ }^{15}$

In clinical practice, the decrease in LVEF is usually asymptomatic, and the trastuzumab package insert recommends baseline LVEF evaluation and reassessment every 
3 months during and upon completion of the treatment. ${ }^{21}$ In our patient, given the lack of symptoms and the excellent tolerance of the drug for a prolonged period of time, echocardiograms were done every 4 months.

The treatment of trastuzumab-associated cardiotoxicity with beta blockers (BB), angiotensin-converting enzyme inhibitors (ACE-I) or angiotensin receptor blockers (ARB), or a combination of these agents, remains empirical, and further randomized clinical trials are needed in order to demonstrate their efficacy.

Trastuzumab-associated cardiotoxicity treatment should be implemented in accordance with the various published guidelines. For instance, the American Association of Heart Failure Guidelines indicate that asymptomatic decreased LVEF below $40 \%$ is an indication for therapy with $\mathrm{BB}$, ACE-I, or ARB. ${ }^{22}$ Also, ESMO Guidelines recommend to consider treatment with BB or ACE-I if the ejection fraction is less than $50 \%$, and to start treatment if the LVEF is less than $40 \%{ }^{23}$ With careful monitoring, cardiac side effects can be identified early and, based on the published data, in the majority of cases (79\%), LVEF will improve with medical treatment. ${ }^{16}$ In patients with good clinical response to trastuzumab, in which we anticipate a prolonged administration of the drug, even though the patient remains asymptomatic, it might be reasonable to start treatment with a $\mathrm{BB}$, an ACE-I, or a combination of both, if the LVEF declines below $40 \%$. The trastuzumab package insert recommends withholding trastuzumab for at least 4 weeks in either of the following situations: $\geq 16 \%$ absolute decrease in LVEF from pretreatment values, or LVEF below institutional limits of normal with $\geq 10 \%$ absolute decrease in LVEF from pretreatment values. ${ }^{21}$ Trastuzumab may be resumed if, within 4-8 weeks, the LVEF returns to normal limits and the absolute decrease from baseline is $\leq 15 \% .{ }^{21}$ These recommendations are easy to follow and they should also guide the treatment of patients receiving trastuzumab for prolonged periods of time.

At present, there are several ongoing trials addressing the question of pharmacological prophylaxis of cardiotoxicity associated with trastuzumab, using BB or ACE-I. ${ }^{24,25}$

It is important to determine in advance which patients are at risk for trastuzumab-related cardiac side effects. In clinical trials, there are several risk factors associated with trastuzumab-induced cardiotoxicity identified so far: prior treatment with anthracycline treatment; a borderline LVEF; prior treatment with antihypertensive medication; older age; and a body mass index $>25 \mathrm{~kg} / \mathrm{m}^{2} .{ }^{26}$ The patient described here had none of these risk factors, and this may have been also one of the reasons she tolerated trastuzumab so well.
The majority of patients treated with trastuzumab do not develop any side effects related to this drug. As mentioned before, trastuzumab-associated cardiac toxicity is not doserelated and, at present, there are no markers that can either predict which patients will develop cardiac toxicity or, when asymptomatic decrease in LVEF is diagnosed, in which patients LVEF will normalize without resort to treatment.

\section{Conclusion}

Chemotherapy and hormonal treatment play a key role in the treatment of metastatic breast cancer. The debate regarding the continuation of trastuzumab in the metastatic setting after initial progression is not settled yet, and our case suggests that, for some patients, this strategy may be beneficial. Trastuzumab may act synergistically in combination with chemotherapy and hormonal treatment, and could be used as the foundation to which different therapeutic agents are added.

In the metastatic setting, the benefit of using trastuzumab in front-line in patients with Her2/neu-positive disease is clearly proven, but the advantage of continuing trastuzumab after progression on trastuzumab is not as firmly established. ${ }^{3}$ In the absence of a randomized, prospective study addressing directly the different factors associated with LTS, a case to case risk-benefit analysis, taking into consideration the prognostic of the individual patient versus the risk of cardiotoxicity associated with the long-term use of trastuzumab, should be performed. Of note, the 1-year mortality of patients with severe heart failure is less than that for patients with metastatic breast cancer. ${ }^{19}$

In some Her2/neu-positive metastatic breast cancer patients, like our patient, the long-term use of trastuzumab, with careful cardiac monitoring, in combination with chemotherapy and hormonal therapy, may help achieve prolonged survival and maybe even a cure.

\section{Disclosure}

The authors report no conflicts of interest in this work.

\section{References}

1. Dawood S, Broglio K, Buzdar AU, Hortobagyi GN, Giordano SH. Prognosis of women with metastatic breast cancer by HER2 status and trastuzumab treatment: an institutional-based review. J Clin Oncol. 2010;28(1):92-98.

2. Slamon DJ, Leyland-Jones B, Shak S, et al. Use of chemotherapy plus a monoclonal antibody against HER2 for metastatic breast cancer that overexpresses HER2. N Engl J Med. 2001;344(11):783-792.

3. von Minckwitz G, Schwedler K, Schmidt M, et al. Trastuzumab beyond progression: overall survival analysis of the GBG 26/BIG 3-05 phase III study in HER2-positive breast cancer. Eur J Cancer. 2011;47(15):2273-2281. 
4. Littlejohns P. Trastuzumab for early breast cancer: evolution or revolution? Lancet Oncol. 2006;7(1):22-23.

5. Rapiti E, Verkooijen HM, Vlastos G, et al. Complete excision of primary breast tumor improves survival of patients with metastatic breast cancer at diagnosis. J Clin Oncol. 2006;24(18):2743-2749.

6. Cady B, Nathan NR, Michaelson JS, Golshan M, Smith BL. Matched pair analyses of stage IV breast cancer with or without resection of primary breast site. Ann Surg Oncol. 2008;15(12):3384-3395.

7. Ruiterkamp J, Ernst MF, van de Poll-Franse LV, Bosscha K, Tjan-Heijnen VC, Voogd AC. Surgical resection of the primary tumour is associated with improved survival in patients with distant metastatic breast cancer at diagnosis. Eur J Surg Oncol. 2009;35(11):1146-1151.

8. Syrios J, Dokou A, Tsavaris N. Sustained complete remission of human epidermal growth factor receptor 2-positive metastatic breast cancer in the liver during long-term trastuzumab (Herceptin) maintenance therapy in a woman: a case report. $J$ Med Case Rep. 2010;4:401.

9. Beda M, Basso U, Ghiotto C, Monfardini S. When should trastuzumab be stopped after achieving complete response in HER2-positive metastatic breast cancer patients? Tumori. 2007;93(5):491-492.

10. Maciá Escalante S, Rodríguez Lescure A, Pons Sanz V, Martinez Banaclocha N, Guillén Ponce C, Carrato Mena A. A patient with breast cancer with hepatic metastases and a complete response to herceptin as monotherapy. Clin Transl Oncol. 2006;8(10):761-763.

11. Eichbaum MH, Schneeweiss A, Bastert G. Long-term remission of excessive liver metastases in a breast cancer patient with chronic alcohol abuse using a monotherapy with trastuzumab. Anticancer Drugs. 2005;16(2):199-200.

12. Uleer C, Yazdan-Pourfard J, Holland B, Karl-Friedrich B, Moisidis-Tesch C, von Minckwitz G. Long-term partial remission with capecitabine/trastuzumab in a patient with metastatic breast cancer following progression on trastuzumab alone. Breast Care (Basel). 2012;7(1):45-47.

13. Fiteni $F$, Villanueva $C$, Bazan $F$, et al. Long-term survival of patients with HER 2 metastatic breast cancer treated by targeted therapies. Cancer Res. 2012;72(24 Suppl 3):18-22.

14. Yardley DA, Tripathy D, Brufsky AM, et al. Long-term survivor characteristics in HER2-positive metastatic breast cancer. $J$ Clin Oncol. 2012;30 Suppl 27:abstr 133.

15. Tripathy D, Kaufman PA, Brufsky AM, et al. First-line treatment patterns and clinical outcomes in patients With HER2-positive and hormone receptor-positive metastatic breast cancer from registHER. Oncologist. 2013;18(5):501-510.
16. Seidman A, Hudis C, Pierri MK, et al. Cardiac dysfunction in the trastuzumab clinical trials experience. J Clin Oncol. 2002;20(5):1215-1221.

17. Piotrowski G, Gawor R, Stasiak A, Gawor Z, Potemski P, Banach M. Cardiac complications associated with trastuzumab in the setting of adjuvant chemotherapy for breast cancer overexpressing human epidermal growth factor receptor type 2-a prospective study. Arch Med Sci. 2012;8(2):227-235.

18. Ewer MS, Lippman SM. Type II chemotherapy-related cardiac dysfunction: time to recognize a new entity. J Clin Oncol. 2005;23(13):2900-2902.

19. Suter TM, Cook-Bruns N, Barton C. Cardiotoxicity associated with trastuzumab (Herceptin) therapy in the treatment of metastatic breast cancer. Breast. 2004;13(3):173-183.

20. Viani GA, Afonso SL, Stefano EJ, De Fendi LI, Soares FV. Adjuvant trastuzumab in the treatment of her-2-positive early breast cancer: a meta analysis of published randomized trials. BMC cancer. 2007;7:153.

21. Herceptin ${ }^{\circledR}$ (trastuzumab) [package insert]. San Francisco, CA: Genentech; 2014. Available from: http://medlibrary.org/lib/rx/meds/ herceptin-1/.

22. Heart Failure Society of America. HFSA 2010 Comprehensive Heart Failure Practice Guidelines J Card Fail. 2010;16(6):e1-e194. Section 7, Executive Summary; e73-e97.

23. Curigliano G, Cardinale D, Suter T, et al. Cardiovascular toxicity Induced by chemotherapy, targeted agents and radiotherapy: ESMO Clinical Practice Guidelines. Ann Oncol. 2012;23 Suppl 7:vii155-vii166.

24. National Cancer Institute. Lisinopril or Coreg $\mathrm{CR}^{\circledR}$ in Reducing Side Effects in Women With Breast Cancer Receiving Trastuzumab. ClinicalTrials.gov Identifier: NCT01009918.

25. University of Alberta. Multidisciplinary Approach to Novel Therapies in Cardiology Oncology Research (MANTICORE). ClinicalTrials.gov Identifier: NCT01016886.

26. Suter TM, Ewer MS. Cancer drugs and the heart: importance and management. European Heart Journal. 2013;34:1102-1111.
OncoTargets and Therapy

\section{Publish your work in this journal}

OncoTargets and Therapy is an international, peer-reviewed, open access journal focusing on the pathological basis of all cancers, potential targets for therapy and treatment protocols employed to improve the management of cancer patients. The journal also focuses on the impact of management programs and new therapeutic agents and protocols on

\section{Dovepress}

patient perspectives such as quality of life, adherence and satisfaction The manuscript management system is completely online and includes a very quick and fair peer-review system, which is all easy to use. Visit http://www.dovepress.com/testimonials.php to read real quotes from published authors. 